\title{
Relationships between physical activity, quality of life, and age in women attending social groups for the elderly
}

\author{
Relações entre atividade física, qualidade de vida e idade em mulheres que \\ frequentam grupos sociais de idosos
}

\author{
Fabricio de Souza $\mathbb{D}^{1} \bowtie$, Márcia Mendonça Marcos de Souza ${ }^{\mathbb{D}}{ }^{2}{ }^{2}$, Fabiana Schuelter-Trevisol (D) ${ }^{1}$, \\ Daisson José Trevisol $\mathbb{D D}^{1}$ \\ Postgraduate Program in Health Science, University of Southern Santa Catarina. Tubarão, Santa Catarina, Brazil. \\ 2 Physical Education Course, Leonardo Da Vinci University Center. Capivari de Baixo, Santa Catarina, Brazil.
}

How to cite this article:

De Souza F, de Souza MMM, Scuelter-Trevisol F, Trevisol DJ. Relationships between physical activity, quality of life, and age in women attending social groups for the elderly. Sci Med. 2018;28(4):ID30301. DOI: 10.15448/1980-6108.2018.4.30301

\section{ABSTRACT}

AIMS: To analyze factors associated with physical activity levels among older women attending social groups for the elderly.

METHODS: A cross-sectional study was conducted with elderly women enrolled in the Municipal Social Development Foundation in the city of Tubarão, in south Brazil. Sociodemographic and health status variables were evaluated through questionnaires administered during interviews, and by anthropometric evaluation. The level of physical activity was assessed using the Modified Baecke Questionnaire for the Elderly. Quality of life was assessed using the World Health Organization Quality of Life Assessment for older adults.

RESULTS: Out of 306 elderly women included in the study, $214(69.9 \%)$ were defined as physically inactive and $92(30.1 \%)$ were active. The proportion of physically active participants between $60-69$ years of age was $52.2 \%$, between $70-79$ years was $40.2 \%$ and equal or more than 80 years was $7.6 \%(p=0.011)$. No other sociodemographic or anthropometric characteristics were associated with physical activity. In the non-adjusted analysis there was association between physical activity and better quality of life, as well as with fewer diseases. There was a weak negative correlation between physical activity and number of diseases (correlation coefficient $=0.215$ ) and a weak positive correlation between physical activity and quality of life scores (correlation coefficient $=0.284$ ). In the adjusted analysis, physical activity remained as a protection factor for loss of quality of life: prevalence ratio $=0.88(95 \%$ confidence interval $=0.81-0.96), \mathrm{p}=0.003$.

CONCLUSIONS: The study concluded that physical activity in elderly women was associated with better quality of life, even when adjusted for age.

KEYWORDS: health of the elderly; aging; comorbidity; exercise.

\section{RESUMO}

OBJETIVOS: Analisar os fatores associados aos níveis de atividade física em mulheres idosas que frequentam grupos sociais para idosos.

MÉTODOS: Estudo transversal, realizado com mulheres idosas cadastradas na Fundação Municipal de Desenvolvimento Social, na cidade de Tubarão, no sul do Brasil. As variáveis sociodemográficas e de estado de saúde foram avaliadas por meio de questionários aplicados durante as entrevistas e por avaliação antropométrica. O nível de atividade física foi avaliado pelo Questionário Baecke Modificado para Idosos. A qualidade de vida foi avaliada pelo questionário World Health Organization Quality of Life assessment for older adults.

RESULTADOS: Das 306 idosas incluídas no estudo, 214 (69,9\%) foram definidas como fisicamente inativas e 92 (30,1\%) como ativas. A proporção de participantes fisicamente ativas entre 60-69 anos de idade foi de 52,2\%, entre 70-79 anos foi de 40,2\% e igual ou maior que 80 anos foi de $7,6 \%(p=0,011)$. Nenhuma outra característica sociodemográfica ou antropométrica foi associada à atividade física. Na análise não ajustada houve associação entre atividade física e melhor qualidade de vida, assim como com menos doenças. Houve correlação negativa fraca entre atividade física e número de doenças (coeficiente de correlação $=0.215$ ) e positiva fraca entre atividade física e nível de qualidade de vida (coeficiente de correlação $=0.284$ ). Na análise ajustada, a atividade física permaneceu como fator de proteção para perda de qualidade de vida: razão de prevalência $=0,88$ (intervalo de confiança $95 \%=0,81-0,96$ ), $\mathrm{p}=0,003$.

CONCLUSÕES: O estudo concluiu que a atividade física em mulheres idosas foi associada à melhor qualidade de vida, mesmo na análise ajustada por idade.

DESCRITORES: saúde do idoso; envelhecimento; comorbidade; exercício. 
Abbreviations: BMI, body mass index; FMDS, Municipal Social Development Foundation; PA, physical activity; QOL, quality of life; WHO, World Health Organization; WHOQOL-OLD, World Health Organization Quality of Life assessment for older adults; WHR, waist-to-hip ratio.

\section{INTRODUCTION}

The population's life expectancy has increased worldwide, and there is a significant increase in the world's elderly population [1]. This increase brings a certain concern, because living longer should mean the possibility to live a full life [2]. In this aspect, a key component during the aging process is quality of life (QOL) [3,4]. QOL concepts are very widespread and diverse, but according to the World Health Organization Quality of Life assessment for older adults (WHOQOL-OLD), the QOL for the elderly is based on the evaluation of the physical, psychological, social, cultural, mental, and spiritual domains [5]. However, QOL is a subjective self-assessment, depending upon a number of factors, such as sociocultural level, age group, and the individual's aspirations [6].

Several factors are extremely relevant in relation to QOL of elderly people, especially health conditions $[3,4,7]$, practice of physical activity (PA) $[8,9]$ and social relationships [10]. Good health conditions are closely linked to good QOL, since the higher the number of morbidities, the lower the QOL index is $[4,7]$. The American College of Sports Medicine emphasizes that adequate PA levels may provide a reduction in the natural physiological effects of aging by increasing the active life expectancy and limiting the development and progression of chronic diseases and disabling conditions [11]. However, despite the possible benefits provided by adequate PA levels, a large portion of the elderly population is considered to be insufficiently active $[12,13]$. An intense social life also seems to increase quality of life and longevity among the elderly, which suggests that social relationships are important factors for physical and mental well-being at older age [10].

Most studies that investigated the associations between PA levels and QOL for the elderly neither have included a control group with potentially reliable factors tested so far, nor did they analyze several important variables that can directly affect QOL, which limits the conclusions that could be drawn $[8,14]$. Given that QOL constantly changes over time and has great importance when it comes to the elderly, research in this area is very relevant, since it will provide significant inputs for the design and implementation of appropriate policies and programs related to QOL improvement. Although literature emphasizes the importance of QOL for the elderly, few studies have investigated QOL among older people engaged in social activities. These studies are important because they allow us to identify factors associated with QOL of individuals engaged in similar social activities. Thereby, the aim of this study was to assess physical activity levels and analyze factors associated with quality of life of older women attending social groups for the elderly.

\section{METHODS}

A cross-sectional study was conducted among active and inactive elderly women enrolled in the Municipal Social Development Foundation (FMDS) of Tubarão, a city in southern Brazil. In 2015, the FMDS had about 800 registered elderly living in 21 districts of the municipality, distributed in 25 groups, which met weekly for cultural and social activities. The population consisted of elderly women aged 60 years and older, residing within the municipality of Tubarão, who were non-institutionalized and participated in the FMDS meetings for elderly people.

A sample size calculation was made using the OpenEpi program. For statistical analysis, 95\% confidence intervals and an $\alpha$-error $=5 \%$ were computed, with an unknown prevalence of $50 \%$ of subjects who had good QOL to maximize the sample size, totaling 260 subjects. It was decided to address only female subjects in this survey because of the little male participation in the program. The sample included the elderly women that attended the groups on the days of data collection and accepted to participate in the study. The participants should be able to understand the questionnaires and sign the free and informed consent form. The participants who did not complete all stages of the study were excluded from the study.

The project was approved by the Research Ethics Committee of the University of Southern Santa Catarina (Opinion number 909600), and the study was conducted according to Resolution 466/2012 of the National Health Council and the declaration of Helsinki for human studies. All participants signed the informed consent.

The study consisted of an interview and assessment of body composition. A team of professionals and undergraduate students in the Health Sciences was formed to collect the data. All team members 
underwent training provided by the leading researcher. A previous administration of the questionnaire was made to $10 \%$ of the sample population for calibration and standardization purposes. Data collection was performed from April to June 2015.

An instrument was developed based on questionnaires with validated questions, in addition to questions asked by the authors to identify the participants' characteristics and their clinical status. QOL was assessed using the WHOQOL-OLD questionnaire, which consists of 24 items attributed to six facets, with four items each. For each of the facets, the possible scores can range from 4 to 20 , since each item can score from 1 to 5 . Therefore, the higher the score, the greater the quality of life [15]. The elderly women who scored 66 points and above were sorted into the category of high quality of life, taking the cut-off point score proposed by Chachamovich et al. [16].

PA levels were evaluated through the Modified Baecke Questionnaire for the Elderly (MBQE), using the version suggested by Mazo et al. [17]. It comprises 12 questions related to three domains: activities of daily living; sports; and leisure activities. The activities of daily living domain contain 10 questions, which are answered on a 0 to 3 scale, with 0 meaning "never does the task" and 3 meaning "always does the task". The other domains comprise open-ended questions in which patients report the time of year when they do sports and leisure activities and the amount of time they spend on these activities. For the activities of daily living domain, the final score was calculated by adding up the points assigned to each question and dividing the result by the total number of questions in that domain; for the other domains, the final score was calculated with a code that classifies the energy expenditure level of the given activity. Finally, the three domain scores were added up, and the level of physical activity of the patient was determined. In addition, the study by Bink et al. [18] was used to define the intensity codes of physical activities. The study participants were sorted into two groups, according to the level of PA. Older women who scored less than 9 were classified as physically inactive, and those with a score equal to or greater than 9 were considered as a physically active [19].

The World Health Organization (WHO) recommendation was adopted to assess smoking. According to the WHO, smokers are those who smoke or have smoked 100 cigarettes or more during their lifetime [20]. Anthropometric measurements were taken. The weight was measured in $(\mathrm{kg})$ using a portable digital scale
(TANITA $^{\circledR}$ BF 680 , Tokyo, Japan), with a $150 \mathrm{~kg}$ capacity and $100 \mathrm{~g}$ sensitivity. Height was measured in $(\mathrm{cm})$ using a vertical stadiometer $\left(\right.$ TONELLI $^{\circledR}$ E150 A, Criciúma, Brazil) to an accuracy of $0.1 \mathrm{~cm}$. The height was measured in the orthostatic position using the Frankfurt horizontal plane as a reference. From those measurements, body mass index (BMI) was obtained by calculating the ratio of weight to height squared $\left(\mathrm{kg} / \mathrm{m}^{2}\right)$. The cut-off points for BMI were those proposed by Lipschitz [21], who considered obese elderly subjects those with a BMI $>27 \mathrm{~kg} / \mathrm{m}^{2}$. The waist and hip circumferences were measured by using an anthropometric tape measure (CARDIOMED ${ }^{\circledR}$ WCS, Curitiba, Brazil). The cut-off points for waist-to-hip ratio (WHR) were those proposed by Callaway et al. [22], for whom a WHR less than 0.76 was associated with a low health risk; a WHR 0.76-0.83 was associated with a moderate risk; a WHR 0.84-0.90 was associated with a high risk; and a WHR above 0.90 was associated with a very high risk. All anthropometric measurements were taken using conventional techniques as described by Pollock et al. [23]. Body composition was obtained by electrical bioimpedance, using a Tanita device (TANITA ${ }^{\circledR}$ BC 601, Tokyo, Japan). The electrical bioimpedance test was run according to the manufacturer's recommendations. A body fat percentage of $\leq 26 \%$ was taken as the cut-off point for an ideal body fat percentage as recommended by the American College of Sports Medicine [24].

The collected data were entered into the Epidata version 3.1 software (EpiData Association, Odense, Denmark) and exported for statistical analysis in the SPSS software version 21.0 (IBM, Armonk, New York, USA). Quantitative variables were described as measures of central tendency (mean) and dispersion (side deviation - SD). Qualitative variables were described as absolute numbers and proportions. The Kolmogorov-Smirnov test was used to check the normality of the data. Pearson's chi-square test, Fisher's exact test, and Mann-Whitney's U test were used to examine the association between PA levels and the variables of interest. Prevalence ratios were calculated with $95 \%$ confidence intervals and an $\alpha$-error $=5 \%$. Variables with a $p$-value $<0.20$ were submitted to modified Poisson regression with a robust estimator for adjusted analysis and correction for possible confounding factors. Spearman's correlation test was used to examine the correlation between the variables of interest. p-values $<0.05$ were used to verify the association between variables. 


\section{RESULTS}

The initial sample consisted of 333 subjects. These figures show that only $41.6 \%$ of those enrolled in the FMDS participated actively in the groups. Data collection was performed from April to June 2015. Of the 333 participants, 27 were excluded because they did not complete all stages of the study, resulting in a final sample of 306 elderly women, with a mean age of $71.9 \pm 6.9$ years. Assessment of PA levels revealed that $214(69.9 \%)$ elderly women were physically inactive, and $92(30.1 \%)$ were active. Regarding the sociodemographic data, there was a statistically significant difference between active and inactive subjects related to the age bracket, with predominance of elderly women aged 60-69 years in the active group, and predominance of inactive women aged over 79 years. Table 1 shows the absolute and relative frequencies of the sociodemographic data of the participants, according to their PA levels.

The anthropometric characteristics did not present a statistically significant difference between active and inactive subjects (Table 2). Regarding the BMI measurements, $69.9 \%$ of the study participants were overweight, and only $0.7 \%$ had a low WHR score associated with risk for cardiovascular events. Likewise, only $0.7 \%$ had an ideal body-fat percentage.

A comparison between morbidity of the participants and their PA levels showed there was a statistically significant difference between the active and inactive groups related to diabetes, hypercholesterolemia, osteoporosis, heart failure, and angina variables, with predominance of elderly women with morbidities in the physically inactive group in all variables (Table 3 ).

Table 1. Comparison of sociodemographic data between active and inactive elderly women attending the groups for the elderly in a municipality located in southern Brazil.

\begin{tabular}{|c|c|c|c|c|}
\hline \multirow[b]{2}{*}{ Demographic characteristic } & \multicolumn{3}{|c|}{ Classification of physical activity } & \multirow[b]{2}{*}{ P-value } \\
\hline & $\begin{array}{c}\text { Total } \\
(\mathbf{n}=306) \\
\mathbf{n}(\%)\end{array}$ & $\begin{array}{c}\text { Inactive } \\
(\mathrm{n}=214) \\
\mathrm{n}(\%)\end{array}$ & $\begin{array}{c}\text { Active } \\
(\mathbf{n}=92) \\
\mathbf{n}(\%)\end{array}$ & \\
\hline \multicolumn{5}{|l|}{ Age (years) } \\
\hline $60-69$ & $130(42.5)$ & $82(38.3)$ & $48(52.2)$ & $0.011^{+}$ \\
\hline $70-79$ & $126(41.2)$ & $89(41.6)$ & $37(40.2)$ & \\
\hline$\geq 80$ & $50(16.3)$ & $43(20.1)$ & $7(7.6)$ & \\
\hline \multicolumn{5}{|l|}{ Skin color } \\
\hline Caucasian & $277(90.5)$ & $197(92.1)$ & $80(87.0)$ & $0.163^{+}$ \\
\hline Non-Caucasian & $29(9.5)$ & $17(7.9)$ & $12(13.0)$ & \\
\hline \multicolumn{5}{|l|}{ Marital status } \\
\hline No-steady partner & $182(59.5)$ & $126(58.9)$ & $56(60.9)$ & $0.745^{+}$ \\
\hline Steady partner & $124(40.5)$ & $88(41.1)$ & $36(39.1)$ & \\
\hline \multicolumn{5}{|l|}{ Education (years of school attendance) } \\
\hline Illiterate & $29(9.5)$ & $24(11.2)$ & $5(5.4)$ & $0.552^{\ddagger}$ \\
\hline $1-4$ & $229(74.8)$ & $155(72.4)$ & $74(80.4)$ & \\
\hline $5-8$ & $32(10.5)$ & $25(11.7)$ & $7(7.6)$ & \\
\hline$\geq 9$ & $16(5.2)$ & $10(4.7)$ & $6(6.5)$ & \\
\hline \multicolumn{5}{|l|}{ Working condition } \\
\hline Home/unemployed & $37(12.1)$ & $28(13.1)$ & $9(9.8)$ & $0.417^{+}$ \\
\hline Retired/pensioner & $269(87.9)$ & $186(86.9)$ & $83(90.2)$ & \\
\hline \multicolumn{5}{|l|}{ Lives alone } \\
\hline Yes & $95(31.0)$ & $66(30.8)$ & $29(31.5)$ & $0.906^{+}$ \\
\hline No & $211(69.0)$ & $148(69.2)$ & $63(68.5)$ & \\
\hline \multicolumn{5}{|l|}{ Alcohol } \\
\hline Drinks or has drank & $61(19.9)$ & $45(21.0)$ & $16(17.4)$ & $0.465^{+}$ \\
\hline Never drank & $245(80.1)$ & $169(79.0)$ & $76(82.6)$ & \\
\hline \multicolumn{5}{|l|}{ Smoking } \\
\hline Smokes or has smoked 100 cigarettes or more & $42(13.7)$ & $30(14.0)$ & $12(13.0)$ & $0.820^{+}$ \\
\hline Never smoked 100 cigarettes & $264(86.3)$ & $184(86.0)$ & $80(87.0)$ & \\
\hline
\end{tabular}

+Pearson's chi-square test.

₹Non-parametric Mann-Whitney U test. 
Table 2. Anthropometric characteristics between 303 active and inactive elderly women attending the groups for the elderly in a municipality located in southern Brazil.

\begin{tabular}{|c|c|c|c|c|}
\hline \multirow[b]{2}{*}{ Anthropometric characteristic } & \multicolumn{3}{|c|}{ Classification of physical activity } & \multirow[b]{2}{*}{ P-value* } \\
\hline & $\begin{array}{c}\text { Total } \\
n=306 \\
\text { Mean (SD) }\end{array}$ & $\begin{array}{c}\text { Inactive } \\
(n=214) \\
\text { Mean (SD) }\end{array}$ & $\begin{array}{c}\text { Active } \\
(n=92) \\
\text { Mean (SD) }\end{array}$ & \\
\hline Weight (kg) & $69.2(13.05)$ & $68.6(12.99)$ & $70.6(13.16)$ & 0.187 \\
\hline Height (meters) & $1.52(0.06)$ & $1.52(0.07)$ & $1.53(0.06)$ & 0.115 \\
\hline BMI & $29.76(4.72)$ & $29.68(4.79)$ & $29.95(4.57)$ & 0.689 \\
\hline WHR & $0.90(0.06)$ & $0.91(0.06)$ & $0.90(0.06)$ & 0.150 \\
\hline Body-fat percentage & $43.26(4.76)$ & $43.56(4.56)$ & $42.56(5.14)$ & 0.131 \\
\hline
\end{tabular}

*Non-parametric Mann-Whitney U test.

Table 3. Comparison of reported morbidities between active and inactive elderly women attending the groups for the elderly in a municipality located in southern Brazil.

\begin{tabular}{|c|c|c|c|c|}
\hline \multirow[b]{2}{*}{ Disease } & \multicolumn{3}{|c|}{ Classification of physical activity } & \multirow[b]{2}{*}{ P-value } \\
\hline & $\begin{array}{c}\text { Total } \\
(\mathbf{n}=306) \\
\text { n (\%) }\end{array}$ & $\begin{array}{c}\text { Inactive } \\
(\mathrm{n}=214) \\
\mathrm{n}(\%)\end{array}$ & $\begin{array}{c}\text { Active } \\
(\mathrm{n}=92) \\
\mathrm{n}(\%)\end{array}$ & \\
\hline \multicolumn{5}{|l|}{ Obesity } \\
\hline Yes & $66(21.6)$ & $49(22.9)$ & $17(18.5)$ & $0.389+$ \\
\hline No & $240(78.4)$ & $165(77.1)$ & $75(81.5)$ & \\
\hline \multicolumn{5}{|c|}{ Hypertension } \\
\hline Yes & $225(73.5)$ & $160(74.8)$ & $65(70.7)$ & $0.454+$ \\
\hline No & $81(26.5)$ & $54(25.2)$ & $27(29.3)$ & \\
\hline \multicolumn{5}{|l|}{ Diabetes } \\
\hline Yes & $87(28.4)$ & $70(32.7)$ & $17(18.5)$ & $0.011+$ \\
\hline No & $219(71.6)$ & $144(67.3)$ & $75(81.5)$ & \\
\hline \multicolumn{5}{|c|}{ Hypercholesterolemia } \\
\hline Yes & $163(53.3)$ & $123(57.5)$ & $40(43.5)$ & $0.024+$ \\
\hline No & $143(46.7)$ & $91(42.5)$ & $52(56.5)$ & \\
\hline \multicolumn{5}{|c|}{ Rheumatism, arthritis, gout or lupus } \\
\hline Yes & $121(39.5)$ & $91(42.5)$ & $30(32.6)$ & $0.104+$ \\
\hline No & $185(60.5)$ & $123(57.5)$ & $62(67.4)$ & \\
\hline \multicolumn{5}{|c|}{ Osteoporosis } \\
\hline Yes & $141(46.1)$ & $109(50.9)$ & $32(34.8)$ & $0.009+$ \\
\hline No & $165(53.9)$ & $105(49.1)$ & $60(65.2)$ & \\
\hline \multicolumn{5}{|l|}{ Stroke } \\
\hline Yes & $12(3.9)$ & $9(4.2)$ & $3(3.3)$ & $0.489 \neq$ \\
\hline No & $294(96.1)$ & 205 (95.8) & $89(96.7)$ & \\
\hline \multicolumn{5}{|l|}{ Infarct } \\
\hline Yes & $23(7.5)$ & $14(6.5)$ & $9(9.8)$ & $0.324 t$ \\
\hline No & $283(92.5)$ & $200(93.5)$ & $83(90.2)$ & \\
\hline \multicolumn{5}{|c|}{ Cardiac insufficiency } \\
\hline Yes & $32(10.5)$ & $29(13.6)$ & $3(3.3)$ & $0.004 \ddagger$ \\
\hline No & $274(89.5)$ & $185(86.4)$ & $89(96.7)$ & \\
\hline \multicolumn{5}{|l|}{ Angina } \\
\hline Yes & $51(16.7)$ & $43(20.1)$ & $8(8.7)$ & $0.014 \dagger$ \\
\hline No & $255(83.3)$ & $171(79.9)$ & $84(91.3)$ & \\
\hline \multicolumn{5}{|c|}{ Other diseases } \\
\hline Yes & $64(20.9)$ & $46(21.5)$ & $18(19.6)$ & $0.703+$ \\
\hline No & $242(79.1)$ & $168(78.5)$ & $74(80.4)$ & \\
\hline
\end{tabular}

†Pearson's chi-square test.

‡Fisher's exact test. 
Table 4 presents the QOL scores of the study participants according to the PA levels placed in the adjusted model for age. In this evaluation, the only variables that did not present a statistically significant difference between active and inactive subjects were "death and dying" and "intimacy" variables. All other variables presented statistical significance, the active group showing better QOL scores than the inactive group. QOL assessment revealed that $74.8 \%$ of the participants had a good QOL. With regard to the PA levels, there was a statistically significant difference between active and inactive subjects, with a higher prevalence of active elderly women classified as having good QOL as compared to the inactive group. After the adjusted analysis, the age and QOL variables remained statistically significant (Table 5).

Table 4. Comparison of quality of life scores among active and inactive elderly women attending the groups for the elderly in a municipality located in southern Brazil (mean and standard deviation), placed in the adjusted model for age.

\begin{tabular}{lcccc}
\hline \multicolumn{1}{l}{ Scores } & \multicolumn{2}{c}{ Classification of physical activity } \\
\cline { 2 - 4 } & $\begin{array}{c}\text { Total } \\
\mathbf{n = 3 0 6} \\
\text { Mean }(\mathbf{S D})\end{array}$ & $\begin{array}{c}\text { Inactive } \\
(\mathbf{n = 2 1 4}) \\
\text { Mean (SD) }\end{array}$ & $\begin{array}{c}\text { Active } \\
(\mathbf{n = 9 2}) \\
\text { Mean (SD) }\end{array}$ & P-value* $^{*}$ \\
Overall score & $73.67(11.13)$ & $71.85(10.76)$ & $77.91(10.87)$ & $<\mathbf{0 . 0 0 1}$ \\
Sensory functioning & $73.08(19.53)$ & $69.77(19.94)$ & $80.77(16.21)$ & $<\mathbf{0 . 0 0 1}$ \\
Autonomy & $74.70(16.45)$ & $72.46(16.51)$ & $79.89(15.19)$ & $<\mathbf{0 . 0 0 1}$ \\
Past, present and future activities & $74.67(16.55)$ & $72.58(15.97)$ & $79.55(16.94)$ & $\mathbf{0 . 0 0 1}$ \\
Social participation & $75.10(15.81)$ & $73.13(15.10)$ & $79.69(16.56)$ & $\mathbf{0 . 0 0 2}$ \\
Death and dying & $71.51(23.72)$ & $70.30(24.44)$ & $74.32(21.84)$ & 0.057 \\
Intimacy & $78.35(18.90)$ & $77.83(18.60)$ & $79.55(19.64)$ & 0.643 \\
\hline
\end{tabular}

* Modified Poisson Regression Test with a robust estimator.

Table 5. Variables related to the level of physical activity placed in the adjusted model.

\begin{tabular}{|c|c|c|c|c|}
\hline Characteristics & PR $(95 \% \mathrm{CI})$ & P-value & Adjusted PR (95\% CI) & P-value* \\
\hline \multicolumn{5}{|l|}{ Age (years) } \\
\hline 60-69 & $1.20(1.08-1.33)$ & 0.001 & $1.18(1.07-1.30)$ & 0.001 \\
\hline $70-79$ & $1.13(1.02-1.26)$ & 0.018 & $1.12(1.01-1.24)$ & 0.031 \\
\hline$\geq 80$ & 1 & & 1 & \\
\hline \multicolumn{5}{|c|}{ Have some disease } \\
\hline Yes & $1.23(1.02-1.47)$ & 0.026 & $1.09(0.92-1.28)$ & 0.321 \\
\hline No & 1 & & 1 & \\
\hline \multicolumn{5}{|c|}{ Blood sugar or diabetes } \\
\hline Yes & $0.89(0.82-0.97)$ & 0.007 & $0.94(0.86-1.03)$ & 0.184 \\
\hline No & 1 & & 1 & \\
\hline \multicolumn{5}{|c|}{ High cholesterol or triglyceride levels } \\
\hline Yes & $0.91(0.84-0.99)$ & 0.023 & $0.95(0.88-1.03)$ & 0.222 \\
\hline No & 1 & & 1 & \\
\hline \multicolumn{5}{|c|}{ Rheumatism, arthritis, gout or lupus } \\
\hline Yes & $0.93(0.86-1.01)$ & 0.098 & $0.99(0.91-1.07)$ & 0.838 \\
\hline No & 1 & & 1 & \\
\hline \multicolumn{5}{|c|}{ Osteoporosis or weak bones } \\
\hline Yes & $0.90(0.83-0.97)$ & 0.008 & $0.94(0.87-1.02)$ & 0.130 \\
\hline No & 1 & & 1 & \\
\hline \multicolumn{5}{|c|}{ Cardiac insufficiency } \\
\hline Yes & $0.83(0.75-0.91)$ & $<0.001$ & $0.90(0.80-1.00)$ & 0.063 \\
\hline No & 1 & & 1 & \\
\hline \multicolumn{5}{|l|}{ Angina } \\
\hline Yes & $0.87(0.79-0.96)$ & 0.005 & $0.96(0.86-1.07)$ & 0.475 \\
\hline No & 1 & & 1 & \\
\hline \multicolumn{5}{|l|}{ Quality of life } \\
\hline Below ideal & $0.84(0.78-0.92)$ & $<0.001$ & $0.88(0.81-0.96)$ & 0.003 \\
\hline Good & 1 & & 1 & \\
\hline
\end{tabular}

PR, prevalence ratio.

* Modified Poisson Regression Test with a robust estimator. 
Analysis of the correlations between PA levels and the variables of interest revealed a statistically significant positive correlation between the QOL score and level of PA, with a correlation coefficient of 0.284 (weak). There was also a statistically significant negative correlation between the "number of diseases" variable and PA levels, with a correlation coefficient of 0.215 (weak).

\section{DISCUSSION}

Findings from this study revealed that $74.8 \%$ of the study participants reported having a good quality of life. This percentage was higher than those found in the literature, $67.3 \%$ [4] and $62.15 \%$ [25]. Analysis of the overall mean scores of QOL assessment domains revealed that the surveyed subjects had higher QOL scores in the social participation and intimacy facets. This finding can be attributed to the fact that all participants were involved in social activities [10], and participating in groups for the elderly was an inclusion criterion in the present study. Roncon et al. [3] stated that elderly people who participate in social groups present better QOL than their counterparts.

A comparison of QOL between the active and inactive elderly women revealed a statistically significant difference in the number of subjects classified as having good QOL, a result that was maintained after the adjusted analysis. This finding suggests that the higher the PA levels of elderly people, the better their QOL. This finding is supported by Toscano and Oliveira [9], who also found that active elderly patients had better QOL than inactive ones, which corroborates the propositions of the WHO $[26,27]$ and the American College of Sports Medicine [11]. Analysis of the sociodemographic data revealed that age was the only variable that was different when comparing active and inactive elderly women. This difference remained after analysis adjusted for possible confounding factors, presenting a higher proportion of younger women classified as active, which indicates that PA becomes more difficult as they get older. Souza et al. [13] found a similar result, since the proportion of active elderly women decreased with increasing age. Findings from Silva et al. [28] were different from those of the present study, given that the highest percentage of active elderly women was found in the age group above 75 years. This difference can be explained by the fact that the other study was conducted on elderly women who attended a regular program of physical exercise in the community of São Caetano do Sul, São Paulo.
Their findings suggest that PA programs are capable of promoting significant changes in the classification of the PA levels among the elderly population, and can be an important tool to reduce their inactive behavior. This finding highlights the need for practicing regular physical exercises by the elderly population, given the natural tendency to decrease the PA levels as they get older.

A comparison between the facets of the active elderly group scores and those found in other studies $[4,25]$ showed that the scores found in this study were higher in practically all facets. Tavares et al. [4] found the following mean scores in their study: sensory functioning 74.07, autonomy 55.36, past, present and future activities 63.07 , social participation 56.28 , death and dying 73.36, and intimacy 68.78. In another study, the same authors found the following mean scores: sensory functioning 76.42 , autonomy 64.56 , past, present and future activities 68.01 , social participation 66.38, death and dying 74.40, and intimacy 71.49 [25]. The only facet that presented a similar score was death and dying, being this the facet in which the surveyed participants had the lowest scores. This result can be explained by the high mean age of the study participants, since older people commonly have lost more relatives and friends throughout their lives than younger people. Moreover, as years pass by, fear of death increases [29]. This piece of information about fear of death is also important for planning possible psychological interventions in the elderly population, helping them to accept their own finitude and contributing to get good QOL.

The findings from this study demonstrated a high prevalence of inactive elderly women (69.9\%), which is consistent with other studies (62\% [13] and $67.5 \%$ [30]). However, in the study by Silva et al. [28], the prevalence of inactive elderly women was much lower $(15.1 \%)$

The present study found a high prevalence of elderly women who had some disease (96.1\%), similar to that found in other studies $(98.2 \%$ [4] and $87.2 \%$ [7]). Such a high prevalence can be attributed to an accurate diagnosis, since $100 \%$ of the elderly in this study had at least one medical appointment in the last year. Another important fact to be highlighted about diseases is that only $21.6 \%$ of the elderly women reported being obese. However, only $0.7 \%$ had an ideal percentage of body fat. Analysis of the other anthropometric variables revealed the study participants had a low classification related to BMI and WHR, considering the ideal levels for health. This finding indicates that obesity and overweight 
were neither adequately assessed and diagnosed, nor was the information disseminated among the study population. Obesity is a chronic, multifactorial disease that is currently one of the biggest public health issues worldwide. It is also a major risk factor for many diseases, and its detection and treatment are extremely important [31], mainly because the most prevalent comorbidities in the study population belonged to the group of chronic non-communicable diseases [31]. This reality is also found in other studies [4,7,32], which demonstrates the need for special attention to obesity-related health risks.

There was also a negative correlation between PA levels and the number of diseases. This correlation may indicate two situations. The first suggests that healthier older people are more active; the second suggests that high levels of PA may reduce the number of diseases for the elderly people. This is important, given its direct relation with QOL of the elderly, which is reinforced by Tavares and Dias [4], who have stated that the higher the number of morbidities, the lower the QOL.

A strength of the present study was the administration of questionnaires through interviews, which helps interpretation of the outcomes, and minimizes errors, thus providing greater reliability. The assessment of several factors that could affect QOL should also be highlighted as a strength in this study. Another strength was the training and calibration of the data collection team, ensuring standardization of data collection procedures. Furthermore, anthropometric measurements taken by a single evaluator ensured intra-observer agreement.

The cross-sectional design could be mentioned as a limitation of this study, given that it does not allow to establish definite temporal relations between the factors that were examined and the main outcomes. The accuracy of self-reports in ascertaining incident diseases could be questioned, and might be another limitation of this study. Furthermore, restricting the participation of the sampled subjects to only women engaged in the groups for the elderly, thus excluding men, people in hospitals, nursing homes, and in their homes could also be pointed out as a limitation of this study. However, this study investigated a large portion of the elderly population with different characteristics, so the data may be valid for other elderly people as well.

Given the relevance of this subject, further studies should be carried out to investigate how PA levels can affect QOL of the elderly population in other geographical regions. It is also suggested that experimental studies should be conducted to analyze the effects of regular PA practice on health conditions, medication use, and QOL of the elderly population.

The present results demonstrated that active elderly women who participate in social groups for the elderly have higher QOL scores than inactive subjects. Analysis of the correlations between the PA levels and the variables of interest (anthropometric characteristics, sociodemographic data, morbidity, and QOL), allowed us to infer that the higher the level of PA of the elderly, the higher their QOL would be, and fewer would be the number of diseases they will have. However, it should be mentioned that the difference of the age group between the active and inactive groups, as well as the number of morbidities, can be important confounding factors. Given the design of this study, it was impossible to state whether a higher level of physical activity provided better QOL scores or whether higher QOL scores provided better levels of physical activity.

The outcomes of this study should alert public authorities, health professionals, and the whole society, because they revealed better QOL scores among active elderly women, with a tendency to decrease the PA levels as they get older. It is important to highlight the many benefits provided by regular practice of PA. Different strategies should be developed to encourage the regular practice of PA among the elderly population.

\section{NOTES}

Funding

We are grateful to the Brazilian Coordination for Improvement of Higher Education Personnel (Coordenação de Aperfeiçoamento de Pessoal de Nível Superior - CAPES), for granting a PhD scholarship to the first author.

\section{Conflicts of interest disclosure}

The authors declare no competing interests relevant to the content of this study.

\section{Authors' contributions}

All the authors declare to have made substantial contributions to the conception, or design, or acquisition, or analysis, or interpretation of data; and drafting the work or revising it critically for important intellectual content; and to approve the version to be published.

Availability of data and responsibility for the results

All the authors declare to have had full access to the available data and they assume full responsibility for the integrity of these results. 


\section{REFERENCES}

1. United Nations, Department of Economic and Social Affairs, Population Division. World Population Prospects: The 2017 Revision, Key Findings and Advance Tables. Working Paper No. ESA/P/WP/248. New York: United Nations; 2017.

2. Brasil. Ministério da Saúde. Secretaria de Atenção à Saúde. Departamento de Ações Programáticas e Estratégicas. Atenção à saúde da pessoa idosa e envelhecimento/Ministério da Saúde, Secretaria de Atenção à Saúde, Departamento de Ações Programáticas e Estratégicas, Área Técnica Saúde do Idoso. Brasília: Ministério da saúde; 2010.

3. Roncon J, Lima S, Pereira MG. Quality of Life, Psychological Morbidity and Family Stress in Elderly Residing in the Community. Psic Teor Pesq. 2015;31(1):87-96. https://doi.org/10.1590/0102-37722015011637087096

4. Tavares DMS, Dias FA. Functional capacity, morbidities and quality of life of the elderly. Texto contexto - enferm. 2012;21(1):112-20. https://doi.org/10.1590/S0104-07072012000100013

5. The World Health Organization Quality of Life assessment (WHOQOL): development and general psychometric properties. Soc Sci Med. 1995;41(10):1403-9. https://doi.org/10.1016/0277-9536(95)00112-K

6. Bowling A, Gabriel Z, Dykes J, Dowding LM, Evans O, Fleissig A, Banister D, Sutton S. Let's ask them: a national survey of definitions of quality of life and its enhancement among people aged 65 and over. Int J Aging Hum Dev. 2003;56(4):269-306. https://doi.org/10.2190/BF8G-5J8L-YTRF-6404

7. Virtuoso JF, Mazo GZ, Menezes EC, Cardoso AS, Dias RG, Balbé GP. Morbidity profile and the standard of access to health services for elderly practitioners of physical activities. Cienc Saude Coletiva. 2012;17(1):23-31. https://doi. org/10.1590/S1413-81232012000100005

8. Vagetti GC, Barbosa Filho VC, Moreira NB, Oliveira Vd, Mazzardo O, Campos Wd. Association between physical activity and quality of life in the elderly: a systematic review, 2000-2012. Rev Bras Psiquiatr. 2014;36(1):76-88. https:// doi.org/10.1590/1516-4446-2012-0895

9. Toscano JJO, Oliveira ACC. Quality of life in elderly subjects with different levels of physical activity. Rev Bras Med Esporte. 2009;15(3):169-73. https://doi.org/10.1590/S1517-86922009000300001

10. Lima Cabral R, Santos S, Barbosa Menezes K, Albuquerque A, Medeiros A. Social factors and the improvement of the quality of life of the elderly: a systematic review. Rev Enferm UFPE on line. 2013;7(5):1434-42.

11. American College of Sports Medicine, Chodzko-Zajko WJ, Proctor DN, Fiatarone Singh MA, Minson CT, Nigg CR, Salem GJ, Skinner JS. American College of Sports Medicine position stand. Exercise and physical activity for older adults. Med Sci Sports Exerc. 2009;41(7):1510-30. https://doi.org/10.1249/MSS.0b013e3181a0c95c

12. Dumith SC, Hallal PC, Reis RS, Kohl HW 3rd. Worldwide prevalence of physical inactivity and its association with human development index in 76 countries. Prev Med. 2011;53(1-2):24-8. https://doi.org/10.1016/j.ypmed.2011.02.017

13. Souza AM, Fillenbaum GG, Blay SL. Prevalence and correlates of physical inactivity among older adults in Rio Grande do Sul, Brazil. PLoS One. 2015;10(2):e0117060. https://doi.org/10.1371/journal.pone.0117060

14. Oliveira AC, Oliveira NMD, Arantes PMM, Alencar MA. Quality of life in elderly people who practice physical activity a systematic review. Rev Bras Geriatr Gerontol. 2010;13(2):301-12. https://doi.org/10.1590/S1809-98232010000200014

15. The World Health Organization Quality of Life Assessment (WHOQOL): development and general psychometric properties. Soc Sci Med. 1998;46(12):1569-85. https://doi.org/10.1016/S0277-9536(98)00009-4

16. Chachamovich E, Trentini CM, Fleck MPA, Schmidt S, Power M. Desenvolvimento do instrumento WHOQOL-OLD. In: Fleck MPA organizador. A avaliação de qualidade de vida: guia para profissionais da saúde. Porto Alegre: Artmed; 2008. p. 102-11.

17. Mazo GZ, Mota J, Benedetti TB, Barros MVG. Concurrent validity and reliability (Test-retest) of Modified Baecke Questionnaire for older adults. Rev Bras Ativ Fis Saude. 2001;6(1):5-11.

18. Bink B, Bonjer FH, Van Der Sluys H. Assessment of the Energy Expenditure by Indirect Time and Motion Study. In: Edang K, Andersen KL, Eds. Physical Activity in Health and Disease. Proceedings of the Bertoslos Symposium. Oslo University: Oslo; 1966; p. 207-14.

19. Sedentary Behaviour Research Network. Letter to the editor: standardized use of the terms "sedentary" and "sedentary behaviours”. Appl Physiol Nutr Metab. 2012;37(3):540-2. https://doi.org/10.1139/h2012-024

20. World Health Organization. Guidelines for controlling and monitoring the tobacco epidemic [Internet]. Geneva; 1998 [cited 2018 Sept 04]. Available from: http://www.who.int/iris/handle/10665/42049/

21. Lipschitz DA. Screening for nutritional status in the elderly. Prim Care. 1994;21(1):55-67.

22. Callaway CW, Chumlea WC, Bouchard C, Himes, JH, Lohman TG, Martin AD, Mitchell CD, Mueller WH, Roche AF, Seefeldt VD. Circumferences. In: Lohman TG, Roche AF, Martorell R, editors. Anthropometric standardization reference manual. Champaign: Human Kinetics Books; 1988. p. 39-54.

23. Pollock ML, Wilmore JH, Fox SM. Exercícios na saúde e na doença: Avaliação e prescrição para prevenção e reabilitação. Rio de Janeiro: Medsi; 1993.

24. American College Of Sports Medicine. Manual do ACSM para teste de esforço e prescrição de exercício. (5a ed.). Rio de Janeiro: Revinter; 2000.

25. Tavares DMS, Bolina AF, Dias FA, Ferreira PCS, Haas VJ. Quality of life of elderly. Comparison between urban and rural areas. Invest Educ Enferm. 2014;32(3):401-13. 
26. World Health Organization. Physical activity - Fact sheet [Internet]. Geneva; 2018 [updated 2018 Feb; cited 2018 Sept 04]. Available from: http://www.who.int/mediacentre/factsheets/fs385/en/

27. World Health Organization. Global Strategy on Diet, Physical Activity and Health. Global recommendations on physical activity for health [Internet]. Geneva; 2010 [cited 2018 Sep 04]. Available from: http://www.who.int/dietphysicalactivity/ publications/9789241599979/en/

28. Silva LJ, Azevedo MR, Matsudo S, Lopes GS. Association between levels of physical activity and use of medication among older women. Cad Saude Publica. 2012;28(3):463-71. https://doi.org/10.1590/S0102-311X2012000300006

29. Maués CR, Paschoal SMP, Jaluul O, França CC, Jacob Filho W. Assessment of quality of life: comparison between elderly young and very old. Rev Bras Clin Med. 2010;8(5):405-10.

30. Antonini T, Castro L, Paz JA, Schwanke CHA, Gottlieb MGV, Bittencourt L, Ribeiro EE, Cruz IBM. Association study among physical activity level, cardiovascular risk and the apolipoprotein E polymorphism in elderly. Rev Bras Geriatr Gerontol. 2011; 14(1):27-37. https://doi.org/10.1590/S1809-98232011000100004

31. World Health Organization. Obesity and overweight - Fact sheet № 311 [Internet]. Geneva; 2018 [updated 2018 Feb; cited 2018 Sept 04]. Available from: http:/www.who.int/mediacentre/factsheets/fs311/en/

32. Pereira DS, Nogueira JAD, Silva CAB. Quality of life and the health status of elderly persons: a population-based study in the central sertão of Ceará. Rev Bras Geriatr Gerontol. 2015;18(4):893-908. https://doi.org/10.1590/18099823.2015.14123 